\title{
A BOA VENTURA ANTI-LUSOTROPICALISTA DE UMA TESE MOÇAMBICANA
}

CABAÇO, José Luís. Moçambique: identidade, colonialismo e libertação. São Paulo: Editora Unesp/ANPOCS, 2009. 360 p. ${ }^{1}$

Moçambique: identidade, colonialismo e libertação é a publicação de uma tese de doutorado defendida na Universidade de São Paulo (USP) por um antigo líder da Frente de Libertação de Moçambique (Frelimo), e que recebeu o prêmio de "melhor tese de doutorado" no concurso da Associação Brasileira de Ciências Sociais (Anpocs), na sua edição de 2008. Seu sucesso no Brasil se deve, indubitavelmente, às suas reflexões detalhadas, que fazem em pedações o "lusotropicalismo", principalmente na sua dimensão africana.

Essa tese, com efeito, deve ser recolocada no seu contexto, visto que foi defendida no Brasil após o autor retomar seus estudos notadamente nesse país, décadas depois de ter sido obrigado a abandoná-

\footnotetext{
Esta resenha é uma versão revista e ampliada da que aparecerá simultaneamente, em francês, na revista Outre-Mers. Revue d'histoire, n. 380-381 (2013). Tradução de Angela Lazagna.
}

-los para entrar no movimento de libertação. Ora, o Brasil é a pátria de Gilberto Freyre, o grande sociólogo que praticamente atravessou o século XX. Autor de numerosas obras sobre os laços ambíguos entre senhores e escravos/criados na sociedade patriarcal escravagista e pós-escravagista, é o pai de uma teoria, o "lusotropicalismo", que teve o seu momento de glória e que ele tentou exportar do Brasil à África e à Ásia colonial portuguesas. Freyre, dessa maneira, delimitou uma "área cultural", embora territorialmente muito descontínua e etnicamente heterogênea, porém unificada pelos "métodos específicos" de colonização dos portugueses, mais aptos que os outros europeus para se integrar aos trópicos. A evidência disso era a "mestiçagem". Pois bem, na década de 1950, o regime salazarista português procurou, após alguma hesitação, incorporar essa teoria, exaltando a mestiçagem cultural e até biológica (sob uma hegemonia 
branca), a fim de provar que a obra lusitana não era a simples imposição do Branco, mas uma obra universalista e não colonial/racista, em virtude da "especificidade" desses europeus do Sul, que são os portugueses. Além disso, o lusotropicalismo havia entusiasmado algum tempo muitos sociólogos, antropólogos e historiadores, inclusive franceses. ${ }^{2}$ No entanto, importa ressaltar que, no período subsequente à Segunda Guerra Mundial, a proposição da mestiçagem como fundamento de uma nova civilização não poderia mais que agradar, considerando que a Europa mal abandonava as teorias raciais de 1930-1940. Na realidade, o que Freyre exaltava era mais o modelo patriarcal da época colonial anterior, que ele contrapunha à selvageria capitalista moderna, do que a miscigenação enquanto tal. Aliás, é por isso que, jovem, expressara opiniões positivas sobre o velho Sul norte-americano. Sua nostalgia é estética, embora ele tenha criado um modelo de "democracia étnica e social". ${ }^{3}$ E uma leitura atenta da sua obra revela de maneira explícita que a miscigenação é concebida, em primeiro lugar, ainda que não exclusivamente, como expansão da

Lucien Febvre, diretor dos Annales, não prefaciaria, com propósitos de um entusiasmo delirante, a versão francesa de Casa grande \& senzala, traduzida por Roger Bastide em 1952?

3 Embora G. Freyre tenha empregado algumas vezes a expressão "democracia racial", que não era sua, ele sempre preferiu utilizar a primeira. luso-europeanidade. Tanto no Brasil como em outros lugares no Ocidente, o modelo foi bem-sucedido ao apresentar um Brasil amável.

É por esse motivo que José Luís Cabaço foi obrigado a demonstrar, logrando-o perfeitamente depois de Mário Pinto de Andrade (sociólogo angolano), que, apesar da sua popularidade no Ocidente, o lusotropicalismo teve uma influência muito débil sobre a geração africana que se formava no final dos anos de 1940 e ao longo da década de 1950 e que comandaria a luta nas colônias portuguesas. O lusotropicalismo foi imediatamente denunciado por esses anticolonialistas que não tinham intenção alguma de criar "novos Brasis", nem mesmo nas ilhas de Cabo Verde. Como diz Omar Ribeiro Thomaz, no seu prefácio ao livro, após

[...] o início da guerra, o luso-tropicalismo não era tema entre os promotores dos movimentos de libertação nacional. Merecia atenção enquanto aquilo que era: ideologia perpetuadora do poder colonial português (p. 16).

Um fato histórico é que o lusotropicalismo não teve um papel importante na formação intelectual dessa geração.

Dito isso, é possível se surpreender que, numa data tão tardia, o ano de 2008, essa acusação contra o lusotropicalismo aplicado à África tenha tido um eco tão grande. Com efeito, o lusotropicalismo e a sua tradução política de "democracia étnico- 
-social” são agora denunciados, há muitos anos, como a negação (ou, ao menos, a relativização explícita) da segregação sociorracial no Brasil e, a fortiori, não possuem nenhum fundamento na África. Finalmente, praticamente não são mais defendidos na comunidade internacional de pesquisadores. Por outro lado, os escritos "anti-lusotropicalistas" são, de qualquer maneira, abundantes no Norte do mundo, ${ }^{4}$ assim como no Brasil $^{5}$ - pelo menos no que se refere ao Brasil. Em vista disso, será que essa crítica ao lusotropicalismo, exportado por Freyre para a África, ainda aparentava ser nova, como se tivesse rompido os tabus nos meios de pesquisa das ciências sociais brasileiras? A resposta é certamente positiva, como demonstra a própria história do livro de José Luís Cabaço. Como relata o semanal moçam-

\footnotetext{
4 Além do clássico livro de Gerald J. Bender, Angola under the Portuguese: the Myth and the Reality, Berkeley: University of California Press, 1978 (em português: Angola sob o domínio português: mito e realidade, Luanda: Nzila, 2009), veja-se, por exemplo, o denso dossiê "Lusotropicalisme. Idéologies coloniales et identités nationales dans les mondes lusophones", in D. Couto, A. Enders e Y. Léonard (orgs.), Lusotopie, v. 4 (1997), p. 195-478, <http://www.lusotopie. sciencespobordeaux.fr/somma97.html >; e Cláudia Castelo, O modo português de estar no mundo: o luso-tropicalismo e a ideologia colonial portuguesa (1933-1961), Porto: Afrontamento, 1998.

5 A começar pelo clássico de Florestan Fernandes, A integração do negro na sociedade de classes, São Paulo: Faculdade de Filosofia, Ciências e Letras da Universidade de São Paulo, 1964.
}

bicano Savana, J. L. Cabaço concluíra um bacharelado em sociologia na Universidade de Trento, na Itália, em 1971. Em 2001, ele se candidatou a uma vaga no mestrado em antropologia da Universidade de São Paulo. No entanto, o Conselho Acadêmico dessa universidade, depois de analisar o seu dossiê, propôs o seu ingresso direto no doutorado em antropologia. J. L. Cabaço concluiu os créditos nas disciplinas do curso em 2002 e, orientado pelo professor Kabengele Munanga, ${ }^{6}$ defendeu sua tese, que foi aprovada com distinção e louvor e com a recomendação de publicação de trabalho. ${ }^{7}$

A qualidade intrínseca do trabalho de J. L. Cabaço bem como a sua temática, que alia reflexões sobre o processo moçambicano de libertação à crítica às considerações lusotropicalistas de Gilberto Freyre, ${ }^{8}$ por si sós, sem dúvida, explicam a classificação máxima concedida pela USP. Aliás, no ano seguinte à sua defesa, entre os vinte trabalhos

\footnotetext{
6 Todos os membros da banca - Wilson do Nascimento Barbosa, Beluce Bellucci, Lourenço Joaquim da Costa Rosário e Carlos Moreira Henriques Serrano e o próprio orientador, Kabengele Munanga - eram pessoas sensíveis à problemática da luta anticolonial na África.

7 Savana, Maputo, 5 de outubro de 2007.

8 Principalmente nas suas duas obras consecutivas às suas viagens pela África portuguesa, a convite do governo de António de Oliveira Salazar: Aventura e rotina: sugestões de uma viagem à procura das constantes portuguesas de caráter e ação, Rio de Janeiro: José Olympio, 1953; e Um brasileiro em terras portuguesas, Rio de Janeiro: José Olympio, 1953.
} 
apresentados no concurso do $32^{\circ}$ Encontro Anual da ANPOCS (outubro de 2008), ocorrido em Caxambu, Minas Gerais, foi a tese de J. L. Cabaço a eleita como a melhor tese em ciências sociais, ${ }^{9}$ sendo publicada em 2009. No entanto, pode-se constatar que o livro não suscitou a publicação de muitas resenhas em revistas científicas, ${ }^{10}$ mas ele é frequentemente citado em artigos brasileiros sobre Moçambique.

No que tange à crítica ao lusotropicalismo, encontramos no trabalho de J. L. Cabaço o que dela se pode esperar: a denúncia da negação das relações sociais racializadas, etc. No entanto, deparamo-nos com um outro aspecto muito interessante dessa crítica: a referência ao profundo culturalismo de Gilberto Freyre. J. L. Cabaço se refere, por exemplo, à viagem de Gilberto Freyre à Lunda, na altura distrito da Companhia dos Diamantes de Angola (Diamang). O sociólogo brasileiro se choca com as condições de exploração dos africanos, denunciando-as em seu livro

9 ANPOCS/Marcelo Siqueira Ridenti, Relatório técnico-científico. $32^{\circ}$ Encontro Anual da ANPOCS, 27-31 de outubro de 2008, Caxambu.

10 Tenho conhecimento de três resenhas, todas publicadas em revistas brasileiras: Luiz Maria Veiga, "Uma obra de referência sobre Moçambique", Revista Crioula, n. 8 (2010); Sandro M. de Almeida-Santos, "A invenção de Moçambique", Revista de Antropologia da USP, v. 53, n. 2 (2010), pp. 779-86; Peter Fry, "Pontos de vista sobre a descolonização em Moçambique", Revista Brasileira de Ciências Sociais, v. 26, n. 76 (2011), pp. 207-11.
Aventura e rotina. No entanto, a sua denúncia não se fundamentou em uma explicação do funcionamento do moderno capitalismo colonial: ela foi analisada como uma influência da Bélgica, já que a Lunda faz fronteira com o então Congo Belga. Logo, os portugueses lá abandonavam os seus brandos costumes em virtude da proximidade geográfica do modelo norte-europeu... Outro exemplo de J. L. Cabaço é a crítica de G. Freyre ao constatar que os negros estavam proibidos de entrar no Hotel Polana (onde ele próprio estava hospedado), em Lourenço Marques (Moçambique). Mais uma vez, a explicação de G. Freyre foi culturalista: era a influência sul-africana, e não a decisão política do Governo Geral de Moçambique de agradar a essa rica clientela, a causa dessa proibição...

No entanto, além da análise crítica do lusotropicalismo e da sua anexação pelo regime salazarista nas suas colônias da África, outra temática provavelmente chamou a atenção do júri da ANPOCS: ${ }^{11}$ a das relações entre brancos e negros, não somente nos seus aspectos gerais mas nos pormenores da vida diária. Aliás, isso foi, com toda a razão, percebido por Luiz Maria Veiga, autor de uma das resenhas citadas:

Outra forma de ler este livro, tendo

\footnotetext{
11 A ANPOCS não publica um relatório explicitando as razões da sua escolha da "melhor tese" (ao menos não o encontrei, apesar dos meus esforços); daí o caráter hipotético dessa frase.
} 
em vista a obra de Albert Memmi, é como um novo retrato do colonizado e do colonizador, agora pondo em foco um caso, da África austral, com semelhanças e diferenças daquele apresentado principalmente sobre o colonialismo na África do Norte. Uma das semelhanças que podemos perceber entre o trabalho do moçambicano José Luís Cabaço, do franco-tunisiano Albert Memmi e do martinicano (e, podemos dizer, argelino e africano por adoção) Frantz Fanon é o fato de neles encontrarmos, além da reflexão política, sociológica, antropológica, marcas das próprias vivências dos autores, testemunhos pessoais entremeados àquilo que é matéria de reflexão. ${ }^{12}$

O livro possui, indubitavelmente, pontos fortes. É interessante e de leitura muito agradável, e isso se deve em parte, como bem ressaltou Luiz Maria Veiga, ao fato de o autor também ter se valido das suas próprias lembranças de militante pró-Frelimo, recurso que ele especifica sempre de maneira escrupulosa.

No entanto, não é possível dizer que suas teses anti-lusotropicalistas sejam tão novas se, como já sublinhamos, nos reportarmos à historiografia internacional (e não só à brasileira) dos últimos vinte anos. Qualquer um já um tanto especializado nesse campo ficará desapontado, mas o livro é aconselhável à comunidade dos cientistas sociais em geral, pois ele é um convite à reflexão.

\footnotetext{
12 Veiga, "Uma obra...".
}

O mérito de J. L. Cabaço, ele próprio um antigo líder da Frelimo, é o de não agir como muitos de seus colegas, que ultimamente multiplicam as publicações de "memórias" sem qualquer vestígio de uma reflexão sobre a história do seu movimento. Ao mesmo tempo, o fazem sob a alegação de "não deixar que os outros escrevam a nossa história", e interrompem suas memórias exatamente em 1974-1975 (data da descolonização). José Luís Cabaço é "contra as memórias" — o que é uma pena! Portanto, ele quis refletir sobre a sua experiência, após tantos anos de ativismo político, de um ponto de vista acadêmico. Se o conjunto da obra vai no sentido de confirmar cem por cento as teses da Frelimo, a visão é, contudo, matizada, pois a história da gênese das suas teses e as dificuldades da sua aplicação são analisadas.

Se o livro é convincente no que toca ao lusotropicalismo e às relações de raça, ele levanta, em contrapartida, sérios problemas sobre muitos aspetos da história moçambicana.

Farei, de início, uma crítica metodológica. A história da Frelimo não é linear - o autor o demonstra! —, e graves crises agitaram os seus primeiros anos (embora ela permaneça surpreendentemente estável desde 1975, apesar das mudanças bruscas das circunstâncias). Pois bem, afora o texto de Uria Simango (então vice-presidente da Frente) de denúncia das suas práticas internas, quando do seu ingresso na dissidência e ao qual J. L. Cabaço se referiu 
apenas de passagem, não temos mais do que fontes escritas, e mesmo orais, do campo dos vencedores e favoráveis a eles. Toda a análise que J. L. Cabaço realizou sobre os vencidos se baseia exclusivamente nos textos e relatos da tendência vitoriosa. No entanto, após 1992-1994 (virada pluralista), ter-lhe-ia sido possível entrevistar opositores sobreviventes, ou pesquisar escritos de opositores nos arquivos do SCCIM e da $\mathrm{DGS}^{13}$ na Torre do Tombo em Lisboa. A desigualdade das fontes permaneceria evidente, mas seria amenizada; de qualquer maneira, o problema metodológico deveria ter sido colocado.

Esse erro o conduz, grosso modo, mas sistematicamente, a reproduzir a versão oficial da história, tal como foi publicitada pela cúpula da Frelimo, que considerou o confronto do final dos anos de 1960 entre os políticos-militares de tendência marxista (os ditos "urbanos") e os chamados "nacionalistas puros" (os ditos "rurais") como um confronto entre modernidade versus chefias (ou meios) tradicionais. No entanto, isto é desmentido pelos fatos. Lázaro Nkavandame, ${ }^{14}$ líder maconde que rompe com a Frelimo e, em seguida, se rende aos

\footnotetext{
13 Os SCCIM (Serviço de Centralização e Coordenação de Informações de Moçambique) e a DGS (Direcção Geral de Segurança), a antiga PIDE (Polícia Internacional e de Defesa do Estado), eram, respectivamente, um serviço de inteligência e a temida polícia política da ditadura portuguesa.

14 Os macondes são um povo do Norte de Moçambique e do Sul da Tanganica que entraram bem cedo na luta.
}

portugueses, não é um líder tradicional, mas um comerciante e um empresário perfeitamente moderno, formado durante a emigração na Tanganica pela experiência do capitalismo colonial britânico. Os "chefes tradicionais" macondes - ademais, de um nível hierárquico bastante baixo na sociedade quase acéfala que os macondes constituem - não eram tão "tradicionalistas", uma vez que, como observa o próprio J. L. Cabaço ao citar Luís de Brito, muitos permanecem leais à Frelimo "radicalizada" após a deserção de Nkavandame. Uria Simango, o já citado vice-presidente da Frelimo, que também entra na dissidência (sem nunca se render aos portugueses), não é de modo nenhum um "tradicionalista", nem politicamente, nem em virtude dos seus laços sociais. Ele é um pastor congregacional formado entre Moçambique e Rodésia, cuja trajetória (aliás, "urbana") é, de fato, perfeitamente comparável à de Eduardo Mondlane - o primeiro presidente da Frelimo assassinado em 3 de fevereiro de 1969. É bem possível que também possam ter existido tensões entre "modernistas" e "tradicionalistas". Mas essa oposição — ainda a ser documentada — não resume a grave crise de 19681970. Essa crise diz respeito mais a trajetórias alternativas de modernidade entre políticos-militares (lusófonos, urbanos, muitas vezes oriundos do sul, saídos antes dos escalões mais baixos do setor de serviços ou da função pública colonial portuguesa) e uma ínfima elite comerciante 
ou urbana (que não era funcionária pública, às vezes camponesa, dificilmente lusófona e inclusive anglófona - formada na emigração nas colônias inglesas - , muitas vezes saída do centro e do norte do "país"15). A força de um Eduardo Mondlane além das suas qualidades pessoais óbvias - é que ele poderia fazer a síntese dessas várias trajetórias. Era nascido no Sul, mas sem experiência no aparato colonial do Estado português; filho de um chefe tradicional, formado, sobretudo, na África do Sul e nos Estados Unidos, foi apoiado pelo Departamento de Estado dos EUA, mas era aliado dos "modernistas", cada vez mais de tendência marxista. Essa "capacidade" foi, aliás, a principal razão que levou a DGS a assassiná-lo. ${ }^{16}$

O livro, que diz respeito à dialética entre a luta de libertação e a identidade, poderia, pois, ter resultado mais rico e mais bem documentado sobre as diversas trajetórias do anticolonialismo. ${ }^{17}$ Além disso, atalhos poderiam ter sido evitados, tal como o "tribalismo-inventado-pelo-

15 As aspas ("país") se justificam ao se tratar, na altura, de um espaço colonial não nacional, cuja pertinência era inexistente para uma grande parte da população.

16 É de notar que, na resenha que Peter Fry consagra ao livro, ele aceita completamente a tese da oposição entre uma "revolta rural", tradicional e racializante e um "protesto urbano" moderno e anticolonial (Fry, "Pontos de vista...", p. 208).

17 Michel Cahen, "Moçambique, o "fim da história'... única. Trajectórias dos anticolonialismos em Moçambique", Africana Studia, n. 15 (2010), pp. 195-240. -colonizador", como se a sociedade africana tivesse de esperar os europeus para conhecer uma grande diversidade de identidades e suas divisões. Aliás, isso provocou no livro um grave impasse em relação à Zambézia. O autor recorda como os portugueses tentaram tardiamente, mas não sem eficácia, recuperar as elites muçulmanas do nordeste do país, um esforço que causou sérias dificuldades para a penetração da Frelimo no sul da província de Cabo Delgado (localizada mais ao norte de Moçambique) e na província de Nampula (também no norte, em contiguidade ao sul de Cabo Delgado). ${ }^{18}$ Mas ele inclui a Zambézia nesse caso a fim de explicar o fracasso da Frelimo nessa última província: ela teria sido, pois, obrigada a "saltar" essas três regiões para se implantar no centro-oeste (província de Tete), para então descer em direção ao sul (Manica e Sofala). No entanto, o Islã é completamente minoritário na Zambézia (com exceção do foco do ex-sultanato de Angoche) e, se a Frelimo não logrou manter a frente militar criada em 1964, foi, de um lado, em razão da sua incapacidade de proteger, contra as retaliações portuguesas, as populações que a tinham apoiado no início (no oeste zambeziano) e, de outro, em virtude de uma formação social colonial

\footnotetext{
18 A esse propósito, veja-se o fascinante livro de AbdoolKarim Vakil, Fernando Amaro Monteiro e Mário Artur Machaqueiro. Moçambique. Memória falada do Islão e da guerra, Coimbra: Almedina, 2011.
} 
muito específica (na Baixa Zambézia), que alimentou um anticolonialismo assimilacionista (que poderia ser comparado, em um contexto diferente, àquele de Aimé Césaire) e não separatista. Se é um fato que poucos zambezianos apoiaram a luta de libertação (e que muitos continuam hoje a votar na oposição), isso não tem absolutamente nada a ver com o Islã ou com a etnicidade em si. Apesar de alguns progressos (a tese de Sérgio Chichava, por exemplo ${ }^{19}$ ), ainda resta fazer a história dos movimentos associativos zambezianos, reivindicativos mas não separatistas, que o autor ignora, como muitos outros, ao citar apenas as associações africanas da capital no extremo Sul.

Uma questão nunca é colocada - nem simplesmente citada - e que, não obstante, é capital para a dinâmica da identidade, ou seja, a questão do partido único. Com efeito, foi evidente desde o início que a unidade necessária para a luta não poderia ser outra que a unicidade obrigatória como um cadinho da "nação". A ideologia do partido único está presente na Frelimo desde a sua criação, em 1962..20 Os grupos dissidentes fazem o mesmo - trata-se de uma concorrência para saber

19 Sérgio Chichava, "Le 'vieux Mozambique': études sur l'identité politique de la Zambézie'" (Tese de Doutorado em Ciências Políticas, Université Montesquieu - Bordeaux 4, 2007).

20 Significativamente, desde os seus primeiros estatutos, ela assume a versão stalinista do "centralismo democrático", embora somente adote o "marxismo-leninismo" quinze anos mais tarde. quem será o partido único. O fato de que "foi assim" e de que, naquela época, as democracias ocidentais, a Organização das Nações Unidas, a Organização da Unidade Africana e não apenas os vilões "comunistas" - apoiassem o princípio do partido único (especialmente sob a forma do reconhecimento exclusivo desse ou daquele movimento como "representante único e legítimo do povo de...", que viabilizava o apoio financeiro e militar) não deve impedir um historiador ou um sociólogo de analisar os efeitos deletérios desse princípio durante a luta de libertação e na independência. Isso é tão mais importante que a discussão sobre o princípio do partido único é quase um decalque da discussão sobre o tipo de nação a ser construída: uma nação homogênea, produto rápido do "homem novo", isto é, de um paradigma de modernização autoritária de negação das primeiras nações pré-coloniais, ou uma nação como produto da lenta conjunção de diversas identidades no seio de uma República, vivenciada como uma garantia de liberdade e de progresso social? Tem-se, aliás, a impressão de que a "nação" aparece logo no dia da independência. O livro reproduz, pois, a confusão muito frequente nas ciências sociais entre anticolonialismo e nacionalismo, entre República e nação, entre nação e Estado-nação. ${ }^{21} \mathrm{~A}$ nação não é considerada como uma cristalização histórica de identidade(s); é a Freli-

\footnotetext{
21 Veja-se minha crítica dessas confusões no artigo "Lutte armée d'émancipation anti-
} 
mo que aparece como a criadora da nação (e não apenas do Estado e da República independente), eclipsando a dialética entre as identidades vividas das nações pré-coloniais (o que se chama habitualmente de "etnias") e a comunidade de sentimento anticolonial, gerada pela luta desenvolvida pela Frelimo. Com outras palavras, é isso o que diz Sandro M. de Almeida-Santos em sua resenha:

A agenda política da Frelimo pretendia eliminar as "tribos" para dar espaço à "nação" (p. 280s), mas a invenção de um Estado-nação não eliminou as antigas relações entre as linhagens africanas, e, neste ponto, a pesquisa deixa algo a desejar. Qual a contribuição das tradições africanas para a história social de Moçambique, para a identidade, para a libertação? As relações complexas entre a população [...] africana e as chamadas "autoridades tradicionais", bem como as relações entre essas "autoridades tradicionais" e as "autoridades coloniais" foram exploradas superficialmente. O olhar macroscópico para um "Moçambique" pode ter inibido, em nosso autor, a visão de microscópicos "moçambiques". Algumas passagens no livro permitem entender que os povos africanos são tidos por populações passivas, que

-coloniale ou mouvement de libération nationale? Processus historique et discours idéologique. Le cas des colonies portugaises, et du Mozambique en particulier", Revue Historique, v. 1, n. 637 (2006), pp. 113-38, <http://www.cairn.info/revue-historique-2006-1-page-113.htm>. apenas observaram sua "cultura" ser aniquilada pelo colonizador branco. ${ }^{22}$

Tem-se um pouco a impressão de que J. L. Cabaço não soube ou não quis saber "quão longe é longe demais", ${ }^{23}$ a fim de não desconstruir a sua própria vida - esta, incomum, a de um jovem branco que se juntou à luta anticolonial africana em 1967. Isso não se deve apenas à dificuldade metodológica acarretada pelo fato de ter sido uma testemunha direta e participante, já que ele tinha plena consciência disso ao escrever sua tese, assinalando escrupulosamente o que é fonte e o que é lembrança - o que se configura como uma das riquezas do livro. O fato é que, na análise política da história da Frelimo até 1975, J. L. Cabaço não se distanciou (pelo menos não suficientemente) do paradigma de modernização autoritária (modernidade versus tradição) dessa frente, paradigma que é uma verdadeira cultura política que atravessou os meandros da passagem do "nacionalismo" ao "nacionalismo-revolucionário", deste ao "marxismo-leninismo" e, por fim, à "autoestima" neoliberal dos discursos atuais.

Desse ponto de vista, é de se lamentar que o livro pare em 1975. O leitor dessas linhas deve saber que José Luís Cabaço foi, dentro da Frelimo quando ainda era dirigente, uma das raríssimas pessoas a tentar desenvolver uma compreensão so-

22 Almeida-Santos, "A invenção", p. 784.

23 N. do T. - Francês : "jusqu'où ne pas aller trop loin". 
cial da guerra interna que assolava o país e que tinha, entre suas causas, justamente, os efeitos dos processos de modernização autoritária. Seria, pois, necessário um segundo volume que começasse em 1975 e prosseguisse, por exemplo, até 1991 (data em que J. L. Cabaço se desvincula da política ativa), o que permitiria discutir o que Peter Fry - no decorrer de uma resenha altamente favorável ao livro - pergunta:

[...] preferiria que $\mathrm{o}$ autor tivesse relativizado o conceito de emancipação. Afinal, poder-se-ia argumentar que enquanto os moçambicanos se emanciparam do governo colonial português, no sentido de alcançar a independência política, não deixaram de serem submetidos, em seguida, a outras formas de controle governamental coercitivo. A opção socialista da Fremilo produziu um regime altamente centralizador, planejador e, talvez, até mais insistente na sua "verdade" socialista do que os colonos portugueses tinham sido com seu catolicismo. Como tenho argumentado, não consigo ver tan-

24 Fry, "Pontos de vista...", pp. 208-9.

25 Nas páginas 209-10 da sua resenha, P. Fry reproduz uma carta particular de J. L. Cabaço em que ele conta a sua atividade no seio da direção da Associação dos Naturais de Moçambique. Outras "lembranças analíticas" de J. L. Cabaço do tempo colonial podem ser encontradas em seu artigo "Violência atmosférica e violências subjectivas. Uma experiência pessoal", Revista Brasileira de Ciências Sociais, v. 26, n.76 (2011), pp. 213-8. Ver, também, a entrevista "A PIDE não desconfiava de um branco da Polana" no jornal $O$ País, Maputo, 28 de fevereiro ta diferença entre a política de assimilação dos portugueses durante o "tempo colonial" e a política de conversão dos moçambicanos em novos homens socialistas ao longo do "tempo Samora". ${ }^{24}$

José Luís Cabaço é "contra as memórias", e é por isso que ele se expressou por meio de uma tese de doutorado. Mas é precisamente porque ele próprio poderia fazer a distinção entre história e memória(s) o que seus antigos companheiros de estrada, que atualmente multiplicam relatos de vida, absolutamente não fazem, convencidos de que eles são a história - , que ele deveria escrever suas... memórias, e de maneira alguma interrompê-las em 1975. Seria um tabu refletir, enquanto moçambicano que permanece fiel à "grande família" da Frelimo (para não falar do partido enquanto tal), e por meio de um relato de vida, sobre os processos identitários pós-independência? ${ }^{25}$

Michel Cahen m.cahen@sciencespobordeaux.fr Universidade de São Paulo

de 2012, < http://opais.sapo.mz/index.php/ politica/63-politica/19231-a-pide-nao-desconfiava-de-um-branco-da-polana.html $>$. Sobre o período pós-colonial, alguns elementos podem ser encontrados numa outra entrevista ao J. L. Cabaço, no mesmo jornal de 29 de abril de 2009, "Machel assumiu um cariz autoritário" [título obviamente da redação], <http://www.opais.co.mz/index. $\mathrm{php} /$ entrevistas/76-entrevistas/902-machel-assumiu-um-cariz-autoritario.html $>$. 